\title{
SYARI'AH DALAM PERSPEKTIF PELAKU BISNIS MLM SYARI'AH AHADNET INTERNASIONAL ( Studi Kasus di Kota Semarang )
}

\author{
Choirul Huda, IAIN Walisongo Semarang
}

\begin{abstract}
PT. Abadnet International, a business Multi Level Marketing (MLM) Syariah, is a MLM business operations based on the principles of syari'ah. The business attracted many people from among Muslims because it offers businesses with marketing Islamic halal products and toyyib. No doubt, many Muslims were later merged into the Abadnet MITRANLAGA. Nevertheless, the Muslims interests of this business does not mean not raising the issue. Labeling the word" Syariah" is attached to the naming MLM International Syari'ah Abadnet it needs proper interpretation. Wrong interpretation of the word shariah for the Abadnet International MLM syariah business will bring counterproductive, both for the company, MITRANIAGA and for Islam itself. Seeing this phenomenon, it is through this stydy, researchers are trying to see how far the understanding of the actors (MITRANLAGA) International Abadnet the term shari'ah . Their understanding of Shari'ab will affect the way they work on the syariah business in genera, particularly MLM syariah business
\end{abstract}

Keyword : MLM, mitraniaga, syari'ah.

\section{Pengantar}

Perkembangan bisnis dari waktu ke waktu mengalami grafik peningkatan yang cukup tajam. Jika di masa lalu bisnis hanya dilakukan dengan cara yang cukup sederhana dan didukung oleh sarana seadanya, maka semenjak revolusi industri melanda dunia, tidak ada lagi batas yang mampu mengekang melejitnya sistem bisnis yang banyak bermunculan dan dikembangkan oleh para pakar ekonomi dan bisnis. Maka menjamurlah berbagai sistem bisnis dengan karakteristiknya masing-masing.

Salah satu bisnis yang saat ini banyak diperbincangkan dan mulai diperkenalkan di Indonesia sejak tahun delapan puluhan adalah bisnis dengan 
sistem Multi Level Marketing (MLM). ${ }^{1}$ Dalam pengembangan usaha dan memasarkan produk-produknya, sistem ini dilaksanakan dengan membentuk jaringan (networking). Semakin banyak jaringan yang dicapai, maka usaha yang dijalani akan semakin berkembang. Tak ayal, berbagai bonus dan hadiah akan mengalir pada pihak-pihak yang telah berhasil tersebut.

Bisnis MLM, dalam perkembangannya banyak diminati oleh berbagai kalangan, laki-laki maupun perempuan, dari masyarakat strata ekonomi kelas bawah hingga atas, masyarakat berpendidikan rendah maupun tinggi dan bahkan tidak mengikat pada batasan agama, suku dan ras serta budaya.

Begitu maraknya bisnis MLM ini, hingga dari tahun ke tahun jumlahnya terus mengalami peningkatan. Eufora bisnis MLM melanda banyak kalangan, hingga pada tahun 1996 di Jakarta didirikan perusahaan MLM Syari'ah dengan didukung oleh para ulama dan tokoh-tokoh MUI. Uniknya, MLM tersebut mendeklarasikan dirinya sebagai bisnis MLM berbasis syari'ah, dengan memasarkan produk-produk halal dan toyyib. Sebagaimana MLM yang lain, MLM ini juga memikat banyak anggota. Sebagai MLM pertama di Indonesia yang berlabel syari'ah dan bahkan telah mendapat sertifikat bisnis syari'ah dari MUI pusat tentu memikat minat banyak kalangan dari umat Islam.

Hubungannya dengan istilah syari'ah yang melekat pada MLM Syari'ah Ahadnet Internasional tersebut ada satu hal yang menarik untuk dikaji dan diteliti. Apakah para member (di Ahadnet disebut mitraniaga) yang tergabung di Ahadnet Internasional itu benar-benar memahami makna syari'ah ataukah sekedar mengikuti eufora bisnis jaringan yang baru berkembang pesat di Indonesia? Hal itu bisa diperparah lagi apabila penggunaan istilah syari'ah itu dimanfaatkan oleh pihak-pihak tertentu yang tidak bertanggungjawab untuk meraup keuntungan secara pribadi dengan meninggalkan etika bermuamalah

${ }^{1}$ Bisnis ini mulai dikenal di dunia sejak tahun 1930-an ketika penjualan dengan sistem direct selling dilakukan oleh Avon yang didirikan oleh David Mc Connell di New York. (secara jelas dapat dibaca di: Andrias Harefa, Pesona Bisnis Dirrect selling dan MLM, Jakarta: PT. Gramedia Pustaka Utama, 2000, hal. 17-21). Kemudian sebagai sistem MLM, perusahaan makanan dari California, Amerika Serikat, yaitu Nutrilite adalah pelopornya. Namun sayang, Nutrilite akhirnya pailit pada tahun 1950-an yang kemudian dibeli oleh dua orang "Belanda Kembar Amway" dengan mendirikan Amway Corporation yang operasional usahanya menggunakan system MLM. Indonesia mulai mengenal bisnis MLM melalui CNI yang didirikan pada tahun 1986 dengan nama PT. Nusantara Sun Chorella Tama (NSCT) yang berdomisili dan beroperasi di Bandung. 
dalam Islam. Akhirnya, justru bukan bisnis syari'ahnya yang dikedepankan tetapi keuntungan semata yang diprioritaskan.

Penelitian ini mencoba ingin melihat kenyataan di atas, makna apakah yang dipahami oleh mitraniaga MLM Syari'ah Ahadnet Internasional tentang istilah syari'ah tersebut. Penelitian ini difokuskan hanya pada mitraniaga yang ada di Kota Semarang, mengingat kota ini adalah salah satu kota yang mayoritas penduduknya muslim dan bisnis MLM Syari'ah Ahadnet Internasional cukup berkembang pesat di kota ini.

\section{Bisnis Syari'ah}

Dalam rangka memenuhi kebutuhan hidupnya, manusia diberi kebebasan oleh Allah untuk memilih suatu usaha atau pekerjaan sesuai dengan bakat dan skill yang dimiliki serta motivasi dan lingkungannya masing-masing. Salah satu bidang usaha yang dapat dilakukan oleh manusia ialah berdagang. Berdagang menjadi satu mata pencaharian yang cukup menjanjikan. Islam sendiri tidak melarang dan bahkan menganjurkan perdagangan, asalkan sesuai dengan tuntunan syari'at Allah dan Rasul-Nya,

Sehubungan dengan hal itu, Rasulullah menegaskan bahwa sebaik-baik amal manusia yaitu dari hasil usahanya sendiri dan jual beli yang mabrur sebagaimana dalam hadis :

Dari Rifaa'ah bin Rofi'ah ra, sesunggubnya Nabi Mubammad SAW, pernah ditanya, "pekerjaan apakah yang paling baik?" Nabi menjawab, "pekerjaan seseorang yang dihasilkannya dengan tangannya sendiri dan selurub (pekerjaan) jual beli yang mabrur." (HR. Bazzar dan Hakim). ${ }^{2}$

Al-Qur'an secara tegas juga mengatakan bahwa berdagang itu adalah halal. ${ }^{3}$ Regulasi detail dalam berbagai ayat yang ada dalam al-Qur'an memberikan bukti nyata bahwasanya al-Qur'an bukan saja mengijinkan,

\footnotetext{
2 Imam Muhammad Ismail, Subulus Salam, (Beirut-Lebanon : Darul Kutub Al-Ilmiah, , Cet.I, Juz. III, 1988), hlm. 4.

${ }^{3}$ QS. Al-Baqarah : 275 dan QS. Al-Nisa : 29.
}

Volume IV/Edisi 2/November 2013 
namun justru mendorong dengan keras orang-orang beriman untuk ikut terlibat dalam sebuah perdagangan yang jujur dan menguntungkan.

Legalitas perdagangan ini mengimplementasikan bahwasanya seorang muslim adalah bebas untuk melakukan bentuk transaksi apa saja selama hal itu berada dalam batasan yang diijinkan. Al-Qur'an memberikan kebebasan berbisnis secara sempurna, baik yang bersifat internal maupun eksternal. Pembatasan dalam hal keuangan dan kontrol pertukaran juga dibebaskan karena hal itu menyangkut kebebasan para pelaku bisnis. Kompetisi terbuka yang didasarkan pada hukum natural dan alami, yakni adanya penawaran dan permintaan kebutuhan (supply and demand) juga sangat didorong. ${ }^{4}$

Namun demikian, hendaknya selalu diingat bahwa legalitas dan kebolehan berdagang itu janganlah disalahartikan bahwa hal itu menghapus semua larangan termasuk tata aturan dan norma-norma yang ada di dalam kehidupan berbisnis. Seorang muslim diharuskan untuk melaksanakan secara penuh dan ketat semua etika petunjuk yang ditata oleh al-Qur'an pada saat melakukan semua bentuk transaksi. Para ahli telah meletakkan aturan-aturan tertentu yang harus ditaati oleh mereka yang terlibat dalam kontrak tersebut. ${ }^{5}$

Selanjutnya dalam kebebasan usaha ekonomi ini termuat pula ketentuan mengenai persetujuan mutual. Transaksi bisnis tidak bisa dikatakan telah mencapai sebuah bentuk perdagangan yang saling rela antara pelakunya (tijaratan 'an taradlin minkum), jika di dalamnya masih ada tekanan, penipuan atau mis-statemen yang digunakan oleh salah satu pihak yang melakukan

${ }^{4}$ SM. Yusuf, Economic Justice in Islam, (Lahore : Ah Muhammad Asyraf, 1971), hlm. 44.

5 Aturan yang dihsilkan oleh para pakar hokum itu ialah sebagi berikut : (i) adanya ijab dan qabul (tawaran dan penerimaan) antara dua pihak yang melakukan transaksi, (ii) kepemilikan barang yang ditransaksikan benar dan sah, (iii) komoditas yang ditransaksikan adalah berbntuk mal (atau harta yang bernilai), (iv). Harga yang ditetapkan adalah harga yang wajar, (v). Khiyar al-ru'yah, yaitu adanya opsi bagi pembeli untukl membatalkan kontraknya saat dia melihat komoditas, (vi) Khiyar al-'ayb, yaitu adanya opsi bagi pembeli untukl membatalkan kontraknya saat dia mendapatkan kerusakan (cacat) pada komoditas yang akan diperjualbelikan, (vii) Khiyar al-Syarth, yaitu adanya opsi bagi pembeli untukl membatalkan kontraknya yang trjadi dalam batas tertentu yang ditentukan oleh kedua belah pihak. ( Lihat dalam Muhammad Zafar ad-Din Miftahi, Islam ka Nizham-I Amn, (Mau, U.P : Miftah al-Ulum, 1966), hlm. 203. 
transaksi. Itulah sebabnya al-Qur'an mengecam dan melarang praktek-praktek yang demikan. ${ }^{6}$

Kesepakatan mutual ini sangat penting karena memiliki beberapa tujuan, antara lain untuk menghindari semua bentuk paksaan, ${ }^{7}$ membebaskan dari penipuan, di mana penipuan dan kelicikan apapun bentuknya adalah sangat dikecam oleh al-Qur'an ${ }^{8}$ dan kesepakatan ini akan membersihkan diri dari kedustaan karena perilaku dusta adalah salah satu dosa besar dalam pandangan al-Qur'an. ${ }^{9}$

Dalam hal bisnis/perdagangan ini, Islam juga memberikan petunjuk praktis sebagai landasan etika untuk menciptakan hubungan yang harmonis antara pelaku bisnis, antara lain utang piutang hendaknya ditulis (QS. 2: 282), penjual tidak memaksa pembeli dan tidak bersumpah dalam menjual, kejujuran, keramah-tamahan, penawaran yang jujur dan tidak bertele-tele (najsy), keadilan, dan menghindari kezaliman (QS. 2: 279), serta menarik manfaat dan menolak madlarat. ${ }^{10}$

Selain itu, ada beberapa praktek transaksi dalam bisnis yang diperbolehkan oleh Islam, di samping ada pula beberapa transaksi yang dilarang untuk dilakukan oleh manusia. Secara umum, transaksi yang dibolehkan bisa dikatagorikan dalam tiga bagian besar, yaitu barter, ${ }^{11}$ tunai, ${ }^{12}$ dan kredit. ${ }^{13}$ Dalam fiqh Islam juga dikenal istilah kerjasama bisnis

${ }^{6}$ Dr. Mustaq Ahmad, Business Ethic in Islam, terj. Oleh Samson Rahman ( Jakarta : Pustka Al-Kautsar, 2001), hlm. 96.

${ }^{7}$ Lihat QS. Al-Nisa : 29.

${ }^{8}$ QS. 4 : 2, QS. $7: 85$, QS. 11 : 85-86, QS. 24 : 47-48, QS. $61: 2-3$.

${ }^{9}$ QS. $7: 29$, QS. $57: 25$.

10 Ahmad Azhar Basyir, Refleksi atas Persoalan Keislaman, (Bandung : Mizan, 1993), hlm. 191. Lihat juga dalam M. Quraish Shihab, Secercah Cahaya Ilahi, ( Bandung : Mizan, 2000), hlm. 239-240.

11 Perdagangan barter, yaitu penukaran barang dengan barang diperbolehkan dengan kualifikasi tertentu. Rasulullah SAW pernah menolak apa yang dilakukan Bilal dalam transaksi dengan menukarkan kurma yang memiliki kualitas jelek dengan kualitas yang baik. (Lihat dalam Hamzah adDamuhi, Al-Iqtishad fi al-Islam, (Kairo : Daar al-Anshar, 1979), hlm. 259-260).

12 Penggunaan transaksi dengan cra tunai ini mendapatkan preferensi lebih utama dan lebih dianjurkan oleh Islam. Preferensi tentang transaksi dalam bentuk tunai hamper serupa bentuknya dalam perdagangan dengan system barter dengan komoditas yang sama. Maksudnya adalah untuk menghindari riba. (lihat dalam Dr. Mustaq Ahmad, op. cit., hal. 117)

13 Transaksi dalam bentuk kredit, pembayaran harga uang komoditas itu ditangguhkan pada periode yang ditentukan secara spesifik. ( (lihad dalam Dr. Mustaq Ahmad, Ibid.)

Volume IV/Edisi 2/November 2013 
(perdagangan) yang dikenal dengan istilah syirkah (partnership/kongsi), yaitu kontrak yang dilakukan oleh dua pihak atau lebih untuk melancarkan perdagangan guna mendapatkan sebuah keuntungan. ${ }^{14}$ Syirkah ini terbagi dalam lima katagori, yaitu syirkah al-Mudharabah atau al-Muqaradlah, ${ }^{15}$ syirkab alInaan, ${ }^{16}$ syirkah al-Wujub17, syirkah al-Muwafadhah, ${ }^{18}$ dan syirkah al-'Amal. ${ }^{19}$

Sementara itu, transaksi yang tidak dibolehkan dalam ajaran Islam antara lain riba, ${ }^{20}$ penipuan, ${ }^{21}$ sogok menyogok, gharar (fiktif), perjudian, ${ }^{22}$ transaksi bathil /illegal,23 Ihtikar (penimbunan barang dengan tujuan menaikkan harga), ${ }^{24}$ jual beli paksa, ${ }^{25}$ jual beli barang haram, ${ }^{26}$ monopoli, ${ }^{27} \mathrm{dll}$.

\section{MLM Syari'ah Ahadnet Internasional di Kota Semarang}

MLM Syari'ah Ahadnet Internasional, adalah lembaga bisnis yang menjalankan operasional dan kebijakannya berdasarkan prinsip-prinsip mu'amalah Islam. 28 Perusahaan ini lahir pada tahun 1996 di Jakarta, dilatarbelakangi oleh kepedulian akan kondisi umat Islam Indonesia yang masih terpuruk. Umat Islam yang mayoritas di negeri ini sudah selayaknya

\footnotetext{
${ }^{14}$ SM. Yusuf, op. cit., hal. 37.

15 Ialah kontrak dalam kerjasama bisnis antara capital di satu sisi dan usaha personal/pekerja disisi yang lain. Kontrak semacam ini diharuskan adanya pembagian hsil yang jelas dan disetujui saat pertama kali terjadi kontrak. (lihat dalam SM. Yusuf, op. cit., hal. 37)

${ }^{16}$ Adalah bentuik kerjasaa bisnis antara dua pihak atau lebih, dimana keduanya dalah sebagai pemilik modal dan sekaligus sebagai pekerja. Hasilnya dibagi secara mutualistik sesuai kesepakatan. (Ibid, hal. 32)

17 Adalah bentuk kerjasama bisnis yang dibenarkan antara dua pihak atau lebih atas dasar kredit, yakni tanpa menanamkan modal apapun dari pihak pembeli dalam perdagangan tersebut. (Ibid., hal. 33)

18 Adalah bentuk kerjasama bisni, dimana tiap pihak yang terlibat kontrak sepakat untuk menyatukan semua sumber keuangan merekla dalam rangka menjalankan sebuah kegiatan bisnis. Kedua belah pihak mendapatkan keuntungan dan kerugian ytang sama. (Ibid., hal. 34)

${ }^{19}$ Adalah bentuk kerjasama bisnis antara dua pihak atau lebih yang berdasarkan atas keahlian dan kerja mereka, baik berupa fisik maupun intelektual. (Ibid., hal. 33)

${ }^{20}$ Lih. QS. Al-Baqarah : 275.

${ }^{21}$ Lih. QS. Al-Anfal : 27, al-Muthaffifin : 1-3.

22 Lih. QS. Al-Maidah : 90.

${ }^{23}$ Lih. QS. Al-Nisa' : 29.

${ }^{24}$ Sayyid Sabiq, Fiqh Sunnah, Juz III, (Beirut : Dar al-Fikr, 1997), hlm. 162.

${ }^{25}$ Lih. QS. Al-Nisa' : 29

${ }^{26}$ Sayyid Sabiq, op. cit., hlm. 148.

${ }^{27}$ Lih. QS. Al-Hasyr : 7

${ }^{28}$ Manajemen Ahadnet, Kode etik Mitra Niaga, (Jakarta:PT. Ahadnet Int., t.th.), hal. 3
} 
memiliki kekuatan jaringan agar pemberdayaan potensi bisnis umat dapat tercapai. ${ }^{29}$ Kehadiran MLM Syari'ah juga dilatarbelakangi oleh realitas bahwa produk-produk makanan, minuman, kosmetika dan jutaan jenis barang-barang lainnya, akan masuk ke Indonesia secara bebas, sehingga kontrol status halal atau haramnya tidak begitu jelas dapat dipertanggungjawabkan. ${ }^{30}$

Tidak jauh berbeda dengan MLM pada umumnya, operasional bisnis ini juga memerlukan jaringan dan pihak manajemen memberikan insentif, bonus atau hadiah kepada para distributor (mitraniaga) yang berprestasi atas dasar keadilan. ${ }^{31}$

Adapun kriteria bisnis MLM Syariah adalah sebagai berikut: ${ }^{32}$

1. Produk yang dipasarkan adalah produk halal, thayyib (berkualitas) dan jauh dari syubhat (sesuatu yang masih meragukan).

2. Sistem akad memenuhi kaidah dan rukun jual beli sebagaimana yang terdapat dalam Hukum Islam (fiqh muamalah).

3. Operasional, kebijakan, corporate culture dan sistem akuntansi sesuai dengan syariah.

4. Tidak ada excessive mark up harga, yaitu harga barang dimark up sampai dua kali lipat sehingga anggota terzalimi dengan harga yang amat mahal, tidak sepadan dengan kualitas dan manfaat yang diperoleh.

5. Struktur manajemen memiliki Dewan Pengawas Syariah yang terdiri dari para ulama yang memahami masalah ekonomi.

6. Formula insentifnya adil, tidak menzalimi down line dan tidak menempatkan up line dengan hanya penerima pasif income tanpa bekerja. Up line tidak menerima income dari hasil jerih payah down line.

7. Pembagian bonus mencerminkan usaha masing-masing anggota. 2002, hal. 17.

${ }^{29}$ Tabloid Jurnal Islam, Edisi No. 99 Th. II/27 Safar - 4 Rabiul Awwal 1423 H / 10-16 Mei

30 Ibid.

${ }^{31}$ Manajemen Ahadnet, Fatwa tentang insentif Mitraniaga, (Jakarta: PT. Ahadnet Int., t.th), hal. 12.

32 Manajemen Ahadnet, Buku Panduan PT. Ahadnet Int., (Jakarta: PT. Ahadnet Int., t.th), hal. 22. Lih juga: Agustianto, www.wirausaha.com.

Volume IV/Edisi 2/November 2013 
Syariah dalam Perspektif Pelaku Bisnis MLM Syariah

8. Tidak ada eksploitasi dalam aturan pembagian bonus antara orang yang terdahulu menjadi anggota dengan orang yang terakhir menjadi anggota.

9. Insentif (bonus) yang diberikan jelas angka nisbahnya sejak awal.

10. Tidak menitikberatkan barang-barang tersier ketika masyarakat masih bergelut dengan pemenuhan kebutuhan primer.

11. Cara penghargaan kepada anggota yang berprestasi tidak mencerminkan sikap hura-hura dan pesta pora.

12. Perusahaan MLM tersebut berorientasi pada kemaslahatan ekonomi umat.

Dari paparan di atas paling tidak ada lima acuan dasar yang dipergunakan untuk mengindikasikan apakah bisnis MLM itu syari'ah ataukah tidak, yaitu: (1). Manajemen perusahaan yang terpercaya dengan diawasi oleh dewan pengawas syari'ah dan memiliki visi misi yang selaras dengan ajaran Islam, (2). Produk yang dijual adalah produk halalan toyyiban dan tidak barang haram atau syubhat, (3). Bagi hasilnya adil dan tidak ada unsur riba, judi, serta eksploitasi, (4). Sistem marketingnya mengacu pada kepentingan agama, tidak sekedar memburu keuntungan dunia, dan (5). Sistem pembinaannya dilakukan secara Islami, tidak mengumbar nafsu dan menonjolkan kehidupan glamour dan foya-foya. Lima hal itulah yang dalam penelitian ini dipergunakan sebagai acuan dasar tentang bisnis MLM Syari'ah di mana dengan acuan tersebut kita akan mengetahui sejauh mana pemaknaan yang dikuasai oleh mitraniaga Ahadnet terhadap istilah syari'ah yang melekat pada bisnis MLM yang mereka geluti.

Di Kota Semarang sendiri, MLM ini mulai di kenal sejak 1997, di saat Indonesia sedang di ambang krisis. Meskipun pada awal kemunculannya kurang begitu diminati, namun dalam perkembangan selanjutnya menunjukkan bahwa bisnis ini telah mampu bertahan dan menarik minat banyak kalangan dari umat Islam di Semarang. Label syari'ah yang melekat padanya menjadi daya tarik tersendiri. Keyakinan akan keadilan insentif yang diberikan, produkproduk yang halal dan toyyib yang dipasarkan dan adanya pengawasan dari Dewan Pengawas Stari'ah Ahadnet adalah beberapa di antara yang menyebabkan mengapa MLM ini mudah dterima di masyarakat, khususnya umat Islam di kota Semarang. 
Bapak H. Muh. Arofah, adalah orang pertama yang bergabung sekaligus memperkenalkan Ahadnet kepada masyarakat Kota Semarang. Ia mendirikan mitrasalur (semacam stokis) JTE-0433 yang beralamat di kawasan Jl. Dr. Cipto Semarang. Pada saat mengawali bisnis ini, ia lebih banyak berkonsentrasi pada pendistribusian produk-produk muslim Ahadnet, sehingga jaringan bisnisnya pun belum berkembang pesat. ${ }^{34}$

Awalnya, jumlah mitraniaga Ahadnet masih sangat sedikit. ${ }^{35}$ Namun dengan berjalannya waktu, jumlah mitraniaga tersebut semakin meningkat. Salah satu pendorong peningkatan itu adalah munculnya beberapa mitra salur baru yang turut memperkuat penyebaran bisnis ini. Seperti munculnya Mitrasalur JTE-09 di Ngaliyan yang dikelola oleh Ibu Hj. Noorva Susanti dan JTE-11 yang dikelola oleh Bapak H. Rahayuwono di Banyumanik. Gairah bisnis Ahadnet mulai meningkat dengan bertambahnya mitrasalur tersebut. Mulailah Ahadnet menyebar dan dikenal secara luas di Kota Semarang. Hingga kini sudah banyak leader-leader Ahadnet yang lahir di Kota Semarang. Hal itu berimbas pada jumlah mitraniaga yang terus meningkat dan omset perusahaan yang membumbung naik dari tahun ke tahun. ${ }^{36}$

\section{Syari'ah dalam Pandangan Mitraniaga Ahadnet di Kota Semarang}

Di depan sudah disebutkan bahwa ada 5 acuan dasar yang dipergunakan untuk mengindikasikan apakah bisnis MLM itu syari'ah ataukah tidak. ${ }^{37}$ Namun demikian untuk melengkapi pemahaman kita tentang istilah syari'ah, di sini penulis tuliskan makna kata syari'at, baik makna kebahasaan

33 JTE adalah kode wilayah untuk Propinsi Jawa Tengah. Sedangkan nomor 04 merupakan urutan pendirian mitra salur di wilayah yang bersangkutan.

34 Wawancara dengan Bapak HM. Arofah, tanggal 4 Agustus 2011

35 Saat kehadirannya pertama kali di Kota Semarang pada tahun 1997, jumlah mitraniaga Ahadnet baru mencapai 25 orang. Kemudian di tahun 1998 meningkat menjadi 123 orang, tahun 1999 menjadi 470 orang, tahun 2000 menjadi 855 orang, tahun 2001 menjadi 1.200 orang, dan tahun 2002 mencapai 3.600 orang. Hingga kini sudah puluhan ribu jumlah mitra niaga Ahadnet di Kota Semarang (Hasil observasi penulis di beberapa mitrasalur, yaitu JTE-04, JTE-09 dan JTE-11)

36 Wawancara dengan Ibu Hj. Noorva Susanti, tanggal 6 Agustus 2011.

${ }^{37}$ Lima acuan dasar yang peneliti cantumkan itu merupakan hasil rangkuman dari berbagai sumber, terutama referensi dari manajemen Ahadnet Internasional dan keterangan dari berbagai pihak yang berkompeten di Ahadnet Internasional. 
maupun istilah. Hal itu bermanfaat untuk memperkuat dasar pijakan tentang pemaknaan syari'ah yang dalam hal ini dilabelkan pada bisnis MLM Ahadnet Internasional. Pemaknaan ini menjadi penting karena dengan makna yang dipahami itu akan dapat mencerminkan cara kerja seseorang. Ketika seseorang tidak memahami makna itu dengan baik, maka apa yang dikerjakannya bisa jadi tidak sesuai dengan syari'at yang diusungnya, bahkan bertentangan.

Syari'ah, menurut Ibn al-Manzhur yang telah mengumpulkan pengertian dari ungkapan dalam Bahasa Arab asli dalam bukunya Lisân al'Arab, ${ }^{38}$ secara bahasa mempunyai beberapa arti. Di antara artinya adalah masyra'ah al-mâ' (sumber air). Hanya saja sumber air tidak mereka sebut syarî'ah kecuali sumber itu airnya sangat berlimpah dan tidak habis-habis (kering).

Kata syarî'ah itu asalnya dari kata kerja syara'a. kata ini menurut ar-Razi dalam bukunya Mukhtâr-us Shihah, ${ }^{39}$ bisa berarti nahaja (menempuh), awdhaba (menjelaskan) dan bayyan-al masâlik (menunjukkan jalan). Sedangkan ungkapan syara'a labum - yasyra'u - syar'an artinya adalah sanna (menetapkan). Menurut AlJurjani, syarî'ah bisa juga berarti mazhab dan tharîqah mustaqîmah / jalan yang lurus. ${ }^{40}$ Jadi arti kata syarîah secara bahasa banyak artinya. Ungkapan syari'ah Islamiyah yang kita bicarakan maksudnya bukanlah semua arti secara bahasa itu.

Suatu istilah, sering dipakai untuk menyebut pengertian tertentu yang berbeda dari arti bahasanya. Lalu arti baru itu biasa dipakai dan mentradisi. Akhirnya setiap kali disebut istilah itu, ia langsung dipahami dengan arti baru yang berbeda dengan arti bahasanya. Contohnya kata shalat, secara bahasa artinya doa. Kemudian syariat menggunakan istilah shalat untuk menyebut serangkaian aktivitas mulai dari takbiratul ibram dan diakhiri salam (sebagaimana shalat yang kita kenal). Maka setiap disebut kata shalat, langsung kita pahami dengan aktivitas shalat, bukan lagi kita pahami sebagai doa.

Kata syarỉah juga demikian. Para ulama akhirnya menggunakan istilah syariah dengan arti selain arti bahasanya, lalu mentradisi. Setiap disebut kata syarîah, langsung dipahami dengan artinya secara tradisi itu. Imam al-Qurthubi

\footnotetext{
${ }^{38}$ Ibn al-Manzhur, Lisân al-'Arab, juz I hal.175

${ }^{39}$ Ar-Razi, Mukbtâr ash-Shibuhb, hal. 294

${ }^{40}$ Al-Jurjani, at-Ta'rifât, hal. 167
} 
menyebut bahwa syarìah adalah agama yang ditetapkan oleh Allah Swt untuk hamba-hamba-Nya yang terdiri dari berbagai hukum dan ketentuan. ${ }^{41}$ Hukum dan ketentuan Allah itu disebut syariat karena memiliki kesamaan dengan sumber air minum yang menjadi sumber kehidupan bagi makhluk hidup. Maka menurut Ibn al-Manzhur syariat itu artinya sama dengan agama. ${ }^{42}$

Pengertian syariat Islam bisa kita peroleh dengan menggabungkan pengertian syariat dan Islam. Untuk kata Islam, secara bahasa artinya inqiyâd (tunduk) dan istislâm li Allah (berserah diri kepada Alah). Hanya saja al-Qur'an menggunakan kata Islam untuk menyebut agama yang diturunkan oleh Allah kepada Nabi Muhammad Saw. ${ }^{43}$ Menurut al-Ghazali, syari'at adalah hukum Allah yang berlaku pada benda dan perbuatan manusia, ${ }^{44}$ di mana hukum Allah itu didasarkan pada al-Qur'an dan Hadits.

Dari paparan tentang syari'ah tersebut di atas, paling tidak secara sepintas kita bisa memaknai apa makna syari'ah itu, apalagi ketika ia dilekatkan dengan sebuah bisnis (usaha). Bisnis yang syariah adalah bisnis yang didalamnya melekat hukum-hukum Allah dan Rasul-Nya. Paparan di awal tulisan ini yang menyebutkan adanya beberapa bisnis yang boleh dan tidak boleh dilakukan menurut Agama Islam adalah bagian dari aturan main berbisnis dalam Islam. Penentuan bisnis yang boleh dan tidak boleh dilakukan dalam Islam ditetapkan berdasarkan panduan Allah dan Rasulullah yang termuat di dalam al-Qur'an dan al-Hadits serta diperkuat dengan ijtihad para ulama yang tidak bertentangan dengan al-Qur'an dan al-Hadist.

Bagaimana dengan makna syari'ah menurut pemahaman para mitraniaga Ahadnet? Perlu diketahui bahwa seluruh mitraniaga Ahadnet beragama Islam, karena salah satu syarat untuk menjadi mitraniaga Ahadnet haruslah beragama Islam. Namun mereka berasal dari berbagai kalangan. Mereka datang dari hampir seluruh lapisan masyarakat yang berbeda latar belakang, baik secara ekonomi, sosial maupun pendidikan. Yang menarik adalah, sebagian besar mitraniaga Ahadnet bukan dari kalangan santri

\footnotetext{
${ }^{41}$ Imam al-Qurthubi, Tafsîr al-Qurthubi, juz XVI hal. 163

42 Ibn al-Manzhur, Lisân al-'Arab, juz XI, hal. 631

43 Sebagaimana Firman Allah dalam al-Maidah: 3, "Pada hari ini telah Kusempurnakan untuk kamu agamamu, dan telab Ku-cukupkan kepadamu ni 'mat-Ku, dan telah Ku-ridhai Islam itu jadi agama bagimu."

${ }^{44}$ Imam al-Ghazali, Al-Mustashfâ fî Tlm al-Ushûl, hal. 5.
} 
(maksudnya orang yang secara khusus pernah belajar agama di pondok pesantren). Kebanyakan mereka dari kalangan umum. Memang belum ada data statistik yang menunjukkan tentang perbandingan jumlah mitraniaga Ahadnet yang pernah belajar agama secara khusus di pesantren dengan mitraniaga yang dari luar pesantren. Namun dari pengamatan penulis dan wawancara dengan berbagai pihak, khususnya mitraniaga Ahadnet, penulis memperoleh keterangan yang menguatkan analisa penulis bahwa sebagian besar mitraniaga Ahadnet bukan berasal dari santri pesantren.

Informasi mengenai latar belakang mitraniaga Ahadnet sebagaimana dijelaskan di atas sangat membantu dalam memahami pemahaman mereka tentang makna syari'ah yang melekat pada bisnis MLM Syari'ah Ahadnet Internasional yang mereka ikuti. Misalnya, $\mathrm{Hj}$. Noorva Susanti, salah satu leader Ahadnet menyatakan bahwa, pemahaman mitraniaga Ahadnet terhadap syari'ah dapat terbentuk dengan baik melalui pembinaan. Saat awal mengikuti bisnis ini, para mitraniaga hanya memahaminya secara sederhana bahwa MLM Ahadnet Internasional adalah MLM Islami yang didirikan oleh ulama-ulama Islam dan diperuntukkan bagi umat Islam. ${ }^{45}$

Penjelasan yang tidak jauh berbeda diungkapkan oleh Bapak H. Moh. Arofah, bahwa banyaknya mitraniaga yang antusias menjadi mitra Ahadnet lebih disebabkan karena adanya peluang untuk menjual produk-produk halal, toyyib, dan bebas alkohol. Jika ditanya mengenai apa sih syari'at itu, rata-rata para mitraniaga kesulitan untuk menjelaskannya secara detail. Mereka tidak akan banyak menjelaskan makna syari'ah itu secara panjang lebar. Yang mereka pahami adalah makna aplikatif dari bisnis syari'ah, yaitu bisnis yang Islami, milik umat Islam, menjual produk halal dan toyyib, sistem bonusnya menggunakan sistem bagi hasil dan pembinaannya seperti layaknya pengajian, tidak hura-hura dan foya-foya sebagaimana yang selama ini terjadi di MLM konvensional. 46

Apa yang disampaikan oleh Ibu Hj. Noorva Susanti dan Bapak H. Moh. Arofah tidaklah berlebihan. Ketika peneliti mencoba menghubungi

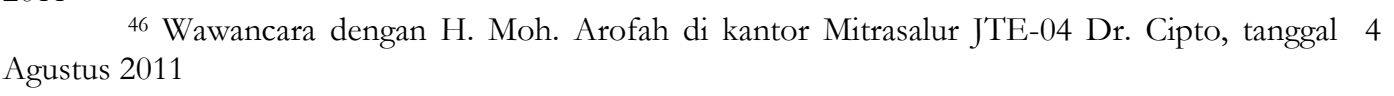

46 Wawancara dengan H. Moh. Arofah di kantor Mitrasalur JTE-04 Dr. Cipto, tanggal 4 
beberapa mitraniaga Ahadnet, tanggapan mereka tentang makna syari'ah tidak keluar dari istilah agama Islam itu sendiri. Artinya syari'ah dimaknai sebagai Islam. Ketika di tanya tentang apa itu MLM syari'ah, maka jawaban mereka adalah MLM Islami. ${ }^{47}$

Tarno, seorang mitraniaga Ahadnet dari Mijen menjelaskan pemahamannya tentang istilah syari'ah, sebagai berikut;

“Syari'ah itu ya Agama Islam. Kalau ada istilah MLM Syari'ah, berarti MLM yang Islami, yang operasionalnya didasarkan pada ketentuan Agama Islam. Saya masuk MLM ini tahun 2003. Saat itu yang ada dalam benak saya adalah umat Islam Indonesia sudah memiliki MLM yang tujuannya untuk membantu meningkatkan perekonomian rakyat. Karena tujuannya mulia, ya saya bergabung. Kalau ditanya tentang syari'ah yang "njlimet" itu ya saya tidak bisa jawab. Yang penting adalah MLM Syari’ah itu MLM yang berdasarkan pada ajaran agama Islam.”48

Hampir senada dengan Tarno, Siti Muhajaroh, guru TK ABA yang tinggal di Karanganyar, Tugu, menyampaikan pengalamannya tentang MLM Syari'ah Ahadnet;

"Tahun 2002 saya sudah bergabung dengan Ahadnet. Saat itu memang saya sedang mencari peluang usaha yang bisa membantu perekonomian keluarga. Apalagi saya guru TK yang honornya belum besar. Ketika ditawari teman untuk bergabung di Ahadnet, saya senang sekali karena MLM ini milik umat Islam. Saya tidak terlalu berpikir mengenai apa itu syari'ah. Bagi saya syariah itu ya Islam. Berarti MLM yang ditawarkan

${ }^{47}$ Beberapa mitraniaga yang sempat peneliti wawancarai antara lain Ibu Umi Syarifah, Bapak Gatot, (masing-masing tinggal di Ngaliyan), Ibu Ratna Rustiana (tinggal di Mangkang), Saudara Eko Prayitno, Bapak Agus Subroto (masing-masing tinggal di pedurungan), Sulipah (tinggal di Perum. Karonsih, Ngaliyan), Rini (tinggal di Krapyak), Andreas (tinggal di Mijen), dan beberapa mitranaga lainnya. Agustus 2011

48 Wawancara dengan Tarno, di kediaman beliau di Desa Wonolopo, Kec. Mijen, tanggal 6 
Syariah dalam Perspektif Pelaku Bisnis MLM Syariah

kepada saya ini adalah MLM Islami yang memang tepat untuk saya yang beragama Islam. Jadi saya tidak terlalu banyak berpikir soal syari'ah..."49

Keyakinan bahwa dengan bergabung menjadi mitraniaga Ahadnet berarti sudah bergabung dengan bisnis yang syari'ah dialami juga oleh Agus Kasturi, ${ }^{50}$ seorang karyawan swasta. Mengingat Ahadnet didirikan oleh para pengusaha Islam yang peduli dengan kondisi umat Islam yang sedang terpuruk, maka keyakinan akan bisnis MLM yang syari'ah sudah muncul sejak awal bergabung. Keyakinan itu semakin mantab ketika manajemen Ahadnet didampingi oleh ulama-ulama kenamaan Indonesia yang keilmuannya di bidang agama Islam sudah tidak perlu diragukan lagi. ${ }^{51}$

Unik lagi dengan apa yang dialami oleh Siti Munawaroh, adik dari Siti Muhajaroh. Awalnya dia tidak mau bergabung ketika ditawari usaha MLM syari'ah ini. Namun ketika ia mengamati perkembangan bisnis kakaknya yang dapat menghasilkan pendapatan tambahan dari Ahadnet, ia mulai tertarik untuk ikut bergabung. Awalnya ia tidak melihat apakah ini bisnis syari'ah ataukah tidak. Pertimbangan utamanya adalah karena kakaknya sukses di bisnis ini. Itulah motivasinya. Tetapi setelah ia menjadi mitraniaga Ahadnet, pembelaannya terhadap Ahadnet sebagai bisnis syari'ah yang sesuai dengan ajaran Islam begitu kuat. Persepsinya tentang kesyari'ahan bisnis ini tercipta seiring dengan berjalannya waktu. ${ }^{52}$

Pemahaman istilah syari'ah oleh sebagian mitraniaga Ahadnet sebagaimana paparan di atas ternyata diamini oleh Bapak H. Moh. Asmu'i Mudzakir, salah seorang ustadz yang juga menjadi mitraniaga Ahadnet. Namun

49 Wawancara dengan Siti Muhajaroh di kediaman beliau di Karanganyar, Tugu, tanggal 10 Agustus 2011

50 Wawancara dengan Agus Kasturi di kediaman beliau di Karanganyar, Tugu, tanggal 11 Agustus 2011

${ }^{51}$ Di antara para tokoh yang menjadi pendiri PT. Ahadnet Internasional adalah H. Ateng Kusnadi, SE., Drs. H. Dhani Ramdhani, Drs. H.M. Hidayat Nur, MBA., MBL., Ir. H. Setyono, SE., dan H. Abdul Halim Said. Sedangkan di antara para ulama yang menjadi Dewan Pengawas Syari'ah PT. Ahadnet Internasional adalah Prof. KH. Ali Yafi, KH Ma'ruf Amin, HM. Syafi'i Antonio, SE., M.Sc., Dr. HM. Nur Hidayat, MBA, MBL, Ir. H. Azwar Anas dan Dr. Adi Sasono. Agustus 2011

${ }^{52}$ Wawancara dengan Siti Munawaroh kediaman beliau di Karanganyar, Tugu, tanggal 10 
ia menegaskan lebih mendalam tentang makna syari'ah tersebut. Secara singkat ia menjelaskan pemahamannya tentang syari'ah sebagai berikut;

"Syari'ah adalah jalan hidup. Jalan hidup seorang mukmin yang lengkap, mencakup ibadah, muamalah dan akhlak. Sehingga ketika seseorang sudah menjadikan syari'ah sebagai penopangnya, maka seluruh kehidupannya harus berpondasikan pada syari'ah, termsuk dalam hal berbisnis. Maka Ahadnet hendaklah menjaga syari'ah itu tidak sekedar dalam mencari keuntungan perusahaan, tetapi juga harus berorientasi pada kemaslahatan umat, sebanyak-banyaknya untuk kebaikan umat, agar umat menjadi maju, bermartabat dan kuat...."53

Dari beberapa pendapat di atas, sekilas bisa dimaknai bahwa pemahaman mitraniaga Ahadnet terhadap istilah syari'ah tidaklah utuh. Mereka memahami istilah syari'ah sebagai sebuah praktik (dalam hal ini praktik berbisnis). Pemahaman mereka tentang syari'ah tidak berawal dari pemahaman istilah syari'ah dalam Islam sebagaimana dijelaskan di depan. Meskipun demikian, hal itu tidak berarti mereka melakukan kesalahan pemahaman tentang istilah syari'ah, asalkan aplikasi syari'ah yang diterapkan dalam bisnis MLM Ahadnet itu tidak bertentangan dengan Syari'ah Islam yang disepakati oleh para ulama jumhur.

Namun demikian, istilah syari'ah yang melekat pada MLM Ahadnet tidak seluruhnya membawa kemudahan bagi mitraniaga Ahadnet dalam menawarkan bisnis ini kepada masyarakat. Bahkan penolakan atas tawaran bisnis ini kerapkali datang justru dari umat Islam itu sendiri. Hal ini sebagaimana pengalaman yang disampaikan oleh Kholid Winandar, seorang guru SMP sekaligus mubaligh muda yang tinggal di Mijen;

“Kata syari'ah memang bisa membantu memudahkan kami dalam menawarkan bisnis MLM ini kepada umat Islam. Tetapi karena beragamnya pemahaman orang tentang syari'ah, apalagi ada istilah fiqh yang sebagian orang memahami berbeda dengan syari'ah menyebabkan

53 Wawancara dengan H. Moh Asmu'i Mudzakir di kediaman beliau di Perum. Beringin Indah, Ngaliyan, tanggal 15 Agustus 2011 
penolakan muncul dari sebagian umat Islam. Penolakan itu muncul karena adanya kekhawatiran mereka apabila bisnis ini meski berlabel syari'ah tetapi kenyataannya tidak syari'ah. Karena itu, sebagai mitra Ahadnet saya berusaha semaksimal mungkin untuk mensinergikan antara konsep dengan aplikasi. Konsep Ahadnet memang disesuaikan dengan Syari'ah. Apalagi ada Dewan Pengawas Syari'ah di sana. Ada KH Ma'ruf Amin yang kyai NU dan Ketua MUI pusat, ada Dr. Muhammad Nur Hidayat, MBA yang anggota Dewan Pengawas Syari'ah MUI Pusat dan lain-lain." ${ }^{54}$

Ahmad Nurkharis, sarjana lulusan IAIN Walisongo Semarang yang sudah beberapa tahun menggeluti bisnis MLM syari'ah ini turut menegaskan bahwa salah satu motivasi utama kenapa seseorang mau bergabung dengan Ahadnet adalah karena faktor peluang usaha yang ditawarkan. Masyarakat memerlukan peluang semacam ini untuk membantu mengentaskan problem finansial mereka. Apalagi peluang ini berlabel syari'ah yang identik dengan umat Islam. Maka tidak heran jika labelisasi syari'ah bagi mereka hanya menunjukkan bahwa bisnis ini adalah bisnis dari umat Islam, oleh umat Islam dan untuk umat Islam. Secara alamiah hal itu akan terbukti, apakah para mitraniaga yang bergabung di Ahadnet itu didasarkan karena faktor ekonomi ataukah karena faktor pemahaman mereka yang benar tentang syari'ah (bisnis syari'ah). Jika semata karena faktor ekonomi, maka ketika mereka gagal berusaha di Ahadnet, bisa dipastikan bahwa mereka akan meninggalkan bisnis ini. Namun jika motivasinya dalam rangka membangun bisnis syari'ah, maka meskipun mereka gagal menjalankan usahanya, kemungkinan mereka masih mau menggunakan produk-produk yang dipasarkan (sebagai pemakai) untuk membantu mensosialisaikan produk-produk milik umat Islam. ${ }^{55}$

Rupanya kondisi semacam itu menjadi perhatian tersendiri bagi manajemen Ahadnet. Ketika ditemui di rumahnya, Ibu Hj. Noorva Susanti, sebagai pengelola mitrasalur JTE-09 menyampaikan beberapa program

\footnotetext{
${ }^{54}$ Wawancara dengan Kholid Winandar di kediaman beliau di Desa Wonolopo, Kec. Mijen, tanggal 6 Agustus 2011

55 Wawancara dengan Ahmad Nurkharis di tempat tinggal beliau di Pesantren Hifdhul Qur'an, Karanganyar, Tugu, tanggal 15 Agustus 2011
} 
pembinaannya terhadap mitraniaga, di mana di antara programnya adalah memperkuat pemaham mereka tentang istilah syari'ah, bisnis syari'ah dan perlunya keberpihakan umat Islam terhadap produk-produk umat sendiri. Hal itu dilakukan agar mitraniaga lebih memahami bisnis yang mereka geluti. ${ }^{56}$ Upaya ini rupanya juga dilakukan oleh beberapa mitrasalur yang lain. Ada kekhawatiran yang sama di antara pengelola mitrasalur apabila istilah syari'ah yang melekat di Ahadnet Internasional justru membebani mitraniaga dalam menjalankan usahanya.

\section{Penutup}

MLM Syari'ah Ahadnet Internasional, sebagai MLM yang lahir dari rahim umat Islam yang diwakili oleh beberapa tokoh Islam yang ada di Jakarta dan mendapat restu dari Majlis Ulama Indonesia (MUI) pusat meerupakan sebuah lembaga yang mengusung syari'ah sebagai bendera, dengan bisnis MLM sebagai kendaraannya. Momentum itu membawa dampak yang tidak sederhana bagi umat Islam pada umumnya dan bagi mitraniaga pada khususnya. Dampak yang tampak nyata di masyarakat adalah adanya keberpihakan dari sebagian umat Islam atas bisnis ini meskipun juga memunculkan gejala kontraproduktif terhadap penggunaan istilah syari'ah, di mana pemaknaan syari'ah di masyarakat tidaklah sebanding dengan semangat penggunaan istilah syari'ah itu sendiri.

Sementara bagi mitraniaga Ahadnet, pemahaman mereka tentang syari'ah juga tidak utuh sebagaimana pemaknaan asli dari istilah syari'ah yang ada. Pemaknaan yang mereka pahami tentang syari'ah adalah agama Islam. Sehingga ketika dikaitkan dengan bisnis MLM Syari'ah, maka pemaknaan yang mereka miliki adalah MLM yang Islami, MLM yang berdasarkan pada ajaran Islam.

Kondisi semacam ini seyogyanya perlu mendapatkan perhatian dari manajemen PT. Ahadnet Inernasional untuk terus melakukan pembinaan terhadap masyarakat pada umumnya dan mitraniaga Ahadnet pada khususnya. Pemaknaan yang benar tentang istilah syari'ah yang dipergunakan akan sangat

${ }^{56}$ Wawancara tanggal 6 Agustus 2011

Volume IV/Edisi 2/November 2013 
Syariah dalam Perspektif Pelaku Bisnis MLM Syariah

membantu operasionalisasi MLM ini ke depannya, karena akan didapatkan mitraniaga yang handal dan militan, di samping edukasi terhadap umat tercapai. Kemungkinannya, nama besar Ahadnet sebagai MLM syari'ah tidak tercemari oleh pemahaman-pemahaman yang keliru dari beberapa pihak, sehingga bagi mitraniaga tidak mengalami kesalahan dalam menjalankan bisnis tersebut. 


\section{DAFTAR PUSTAKA}

Ahmad Azhar Basyir, Refleksi atas Persoalan Keislaman, (Bandung : Mizan, 1993). Andrias Harefa, Pesona Bisnis Dirrect selling dan MLM, Jakarta: PT. Gramedia Pustaka Utama, 2000.

Hamzah ad-Damuhi, Al-Iqtishad fi al-Islam, (Kairo : Daar al-Anshar, 1979).

Ibn al-Manzhur, Lisân al-'Arab, juz I.

Ibn al-Manzhur, Lisân al-'Arab, juz XI.

Imam Muhammad Ismail, Subulus Salam, (Beirut-Lebanon : Darul Kutub AlIlmiah, Cet.I, Juz. III, 1988).

Imam al-Qurthubi, Tafsîr al-Qurthubi, juz XVI.

Manajemen Ahadnet, Buku Panduan PT. Abadnet Int., Jakarta: PT. Ahadnet Int., t.th).

Manajemen Ahadnet, Fatwa tentang insentif Mitraniaga, Jakarta: PT. Ahadnet Int., t.th).

Manajemen Ahadnet, Kode etik Mitra Niaga, (Jakarta:PT. Ahadnet Int., t.th.).

Muhammad Zafar ad-Din Miftahi, Islam ka Niz̧ham-I Amn, (Mau, U.P : Miftah al-Ulum, 1966).

M. Quraish Shihab, Secercah Cahaya Ilahi, (Bandung : Mizan, 2000).

Mustaq Ahmad, Dr., Business Ethic in Islam, terj. Oleh Samson Rahman Jakarta : Pustka Al-Kautsar, 2001).

Sayyid Sabiq, Fiqh Sunnah, Juz III, ( Beirut : Dar al-Fikr, 1997).

SM. Yusuf, Economic Justice in Islam, (Lahore : Ah Muhammad Asyraf, 1971).

Tabloid Jurnal Islam, Edisi No. 99 Th. II/27 Safar - 4 Rabiul Awwal 1423 H / 10-16 Mei 2002.

Agustianto, www.wirausaha.com.

Wawancara dengan Bapak M. Arofah, tanggal 4 Agustus 2011

Volume IV/Edisi 2/November 2013 
Syariah dalam Perspektif Pelaku Bisnis MLM Syariah

Wawancara dengan Ibu Noorva Susanti, tanggal 6 Agustus 2011

Wawancara dengan Bapak Kholid Winandar, tanggal 6 Agustus 2011

Wawancara dengan Bapak Tarno tanggal 6 Agustus 2011

Wawancara dengan Ibu Siti Muhajaroh, tanggal 10 Agustus 2011

Wawancara dengan Ibu Siti Munawaroh, tanggal 10 Agustus 2011

Wawancara dengan Bapak Agus Kasturi, tanggal 10 Agustus 2011

Wawancara dengan Bapak H. Muh. Asmu'i Mudzakir, tanggal 15 Agustus 2011

Wawancara dengan Ibu Umi Syarifah, Bapak Gatot, Ibu Ratna Rustiana, Bapak Agus Subroto, Saudara Eko Prayitno, Sulipah, Rini, Andreas, dll. 